\title{
Estimating the Evaporation from Irrigation Canals in Northwestern China Using the Double-Deck Surface Air Layer Model
}

\author{
Suhua Liu, ${ }^{1}$ Weizhen Wang, ${ }^{1}$ Makito Mori, ${ }^{2}$ and Tetsuo Kobayashi ${ }^{1,3}$ \\ ${ }^{1}$ Cold and Arid Regions Environmental and Engineering Research Institute, Chinese Academy of Sciences (CAS), \\ Lanzhou 73000, China \\ ${ }^{2}$ Faculty of Agriculture, Kochi University, Nankoku 783-8502, Japan \\ ${ }^{3}$ The Society of Agricultural Meteorology of Japan, Fukuoka 812-0016, Japan
}

Correspondence should be addressed to Weizhen Wang; weizhen@lzb.ac.cn

Received 24 August 2015; Revised 26 October 2015; Accepted 3 November 2015

Academic Editor: Xiao-Ming Hu

Copyright ( 2016 Suhua Liu et al. This is an open access article distributed under the Creative Commons Attribution License, which permits unrestricted use, distribution, and reproduction in any medium, provided the original work is properly cited.

\begin{abstract}
The evaporation from irrigation canals was estimated by the aerodynamic method based on the double-deck surface air layer model (called "DSAL model" for short hereafter). The DSAL model describes the surface air layer over a canal as a composite air layer with two sublayers, the lower sublayer and the upper sublayer. The lower sublayer is a few tens of centimeters thick and formed by the flowing water, in which there is no advection; the upper sublayer is over the lower sublayer and formed by the surface wind. The results were compared to those obtained by the heat balance method; field experiments were conducted in the middle reaches of the Heihe River in northwestern China. Results showed that cumulative evaporation instances estimated by the DSAL model were equal in order of magnitude to those by the heat balance method on observed days during the daytime (0700 1900 BST). We infer from these experimental results that the evaporation loss in transport in this region is of the order of one percent at most.
\end{abstract}

\section{Introduction}

Irrigation water is vital to agricultural production in arid land, and it is, in general, transported through canals over a long distance. In China, irrigation canals are classified into five groups which are main canal, branch canal, lateral canal, field canal, and field ditch. In the middle reaches of the Heihe River in northwestern China (Figure 1), the main and branch canals extend for $4,500 \mathrm{~km}$ and $82 \%$ of the two higher classes have been paved with concrete. The total length of the two middle classes is $22,700 \mathrm{~km}, 64 \%$ of which have been paved. If irrigation canals are unpaved, we can readily conceive that a considerable amount of irrigation water is lost due to seepage into the ground before it reaches irrigation fields [1]. The evaporation from water surfaces is another cause of water losses from irrigation canals and it is also considerable in arid regions [2]. However, few attempts have been made to evaluate evaporation loss from a small plot, such as water surface of canals: one reason is the advection caused by running water in the canal and the other reason is the actual operation that is unsuitable and difficulty of applying the evaporation pan or lysimeter technique to the running water.

Methods usually used for estimating open water evaporation are as follows [3]: (1) evaporation pan method, (2) mass balance method or water balance method, (3) energy balance method or heat balance method, (4) aerodynamic method, and (5) combination method. However, only three methods, namely, "evaporation pan method," "heat balance method," and "aerodynamic method," have been applied to estimate evaporation from channels or canals.

In the late 1940s and early 1950s, the paddy rice of the north or highland regions in Japan suffered damage caused by cold weather. Therefore, many water-warming ponds and canals were constructed. Higashi and Hanyu [4] carried out a field experiment at a water-warming canal in Hokkaido, Japan, and analyzed the heat balance on the flowing water in the canal, where they regarded half the pan evaporation at a neighboring observatory as the evaporation from the canal 

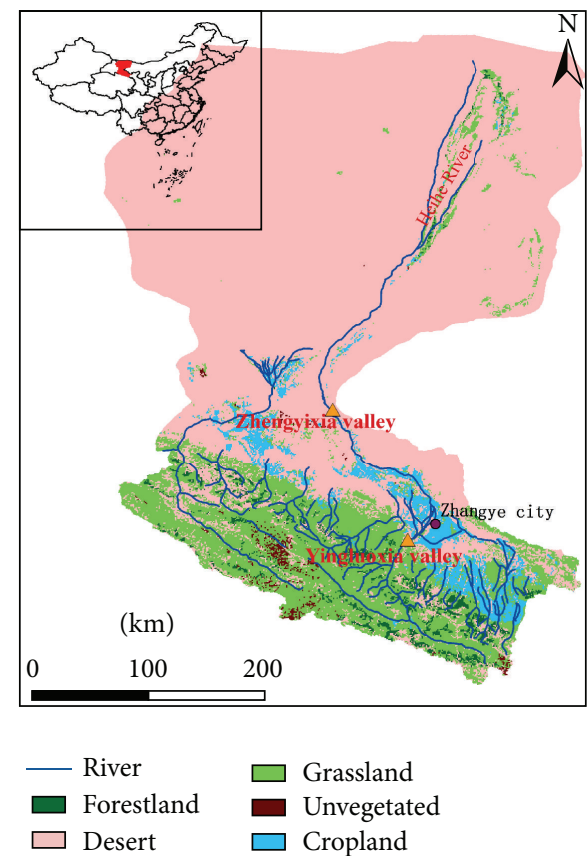

(a)

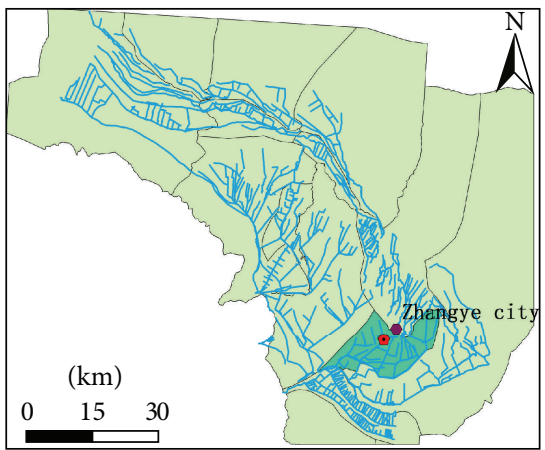

- Observation point Irrigation area
— Canal

Yingke irrigation area

(b)

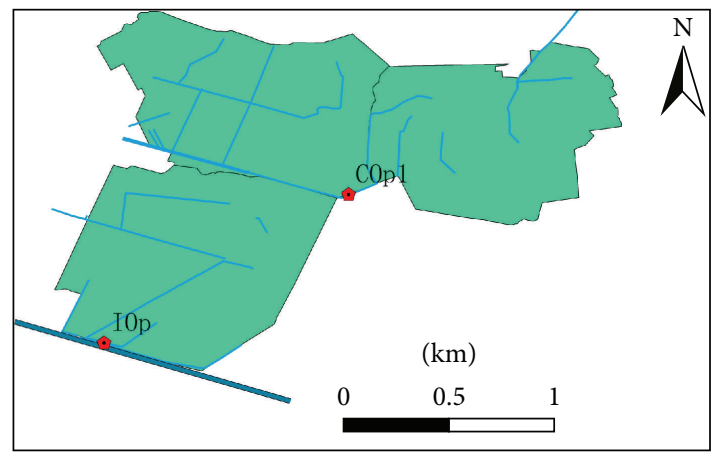

- Observation point Lateral canals
Yingke main canal Irrigated district

(c)

FIGURE 1: The basin of the Heihe River and the study area in the middle reaches of the river near Zhangye City.

without rational grounds. In conducting a field investigation of water losses for three types of channels based on water balance method, Moghazi and Isumail [2] regarded the evaporation rate measured with a Class A pan as a rough estimate of evaporation losses from the channels.

Mihara et al. [5,6] conducted studies based on heat balance method at water-warming ponds and canals in northern Japan. They determined the rate of heat transfer between the running water and the surface air layer, and, as a result, they derived a Dalton-type formula for the latent heat released or absorbed by the running water surface, which is expressed as a product of the difference in vapor pressure between the water surface and the surface air layer. Jobson [7] also derived a Dalton-type formula of evaporation rate from analyzing the heat balance on the flowing water in the San Diego Aqueduct, California. He showed that the evaporation from the channels was a little larger than that from nearby Class A pans on an annual basis. Fulford and Sturm [8] made a comparative experiment according to the heat balance method on an artificially heated water channel and a naturally exposed one in Tennessee, USA. As a result, they concluded that the evaporation from flowing channels, in which the effects of wind fetch can be accurately determined, is needed and the stability-dependent formula, which was devised to include the effect of natural convection by Ryan and Harleman [9], may be more appropriate than the Dalton-type formula for channels.

Kawahara [10] made observations of the balance of heat on the flowing water in a canal within a salt farm in the Seto Inland Sea coastal area, Japan. He used the aerodynamic 
method to describe the rate of evaporation from the canal by assuming that statically neutral conditions prevail in the surface air layer and the water surface is wide enough to apply an eddy transport theory devised by him.

The Dalton-type formulation shows that the evaporation rate under a gentle breeze is greater for canals than for ponds or lakes [7]. This seems to suggest that the evaporation rate increases with the flow speed of water, even if the surface wind speed remains constant.

Kobayashi et al. [11] intended to estimate the evaporation from irrigation canals in the middle reaches of the Heihe River in northwestern China and since the flow speed of water is, in general, larger than $3 \mathrm{~m} / \mathrm{s}$ and also is often larger than the surface wind speed supposed that the evaporation rate depends not only on the surface wind speed but also on the water flow speed and constructed a model called the doubledeck surface air layer (DSAL) model, which is outlined in the next section.

This paper describes field experiments carried out in a high-altitude, arid region in the middle reaches of Heihe River in northwestern China. The objectives of this study are to test the DSAL model against experimental data, to estimate the evaporation from irrigation canals in this region, and to contribute to irrigation technique for good agricultural water productivity $[12,13]$.

\section{Double-Deck Surface Air Layer (DSAL) Model}

In this section the double-deck surface air layer (DSAL) model is outlined [11] and some supplementary considerations are given. Figure 2 shows the schematic diagram of the DSAL formed over the flowing water. This composite surface air layer consists of two sublayers. The lower sublayer is dragged by the flowing water and the flow-wise momentum is transported upward through it (SAL-W), the thickness of which is $\delta$. The upper sublayer is the surface air layer formed over the ground surrounding the stream (SAL) by the surface wind and the wind-wise momentum is transported downward through it. In Figure 2, $\mathbf{U}_{w}$ is the flow velocity of water and $\mathbf{U}_{a}$ is the surface wind velocity, $T_{a}$ is the air temperature, and $e_{a}$ is the water vapor pressure at height $z_{a}$ in the SAL, respectively. The boldface symbols mean that they are vectors and their directions are in general different from each other. The subscripts $\delta$ and $w$ refer to the values at the top and bottom of the SAL-W, respectively. Thus, $\mathbf{U}_{a \delta}$ is the air velocity at the top of the SAL-W, and the average windwise and flow-wise components of the velocity are assumed to be approximately zero when necessary.

Upward water vapor fluxes through the two sublayers, $E_{\mathrm{SAL}-\mathrm{W}}$ and $E_{\mathrm{SAL}}$, can be expressed approximately as the bulk equations:

$$
\begin{aligned}
E_{\mathrm{SAL}-\mathrm{W}} & =A U_{w}\left(e_{w}-e_{a \delta}\right), \\
E_{\mathrm{SAL}} & =B U_{a}\left(e_{a \delta}-e_{a}\right),
\end{aligned}
$$

where $A$ and $B$ are the bulk coefficients for the SAL-W and $\mathrm{SAL}$, respectively. If isothermal conditions and logarithmic

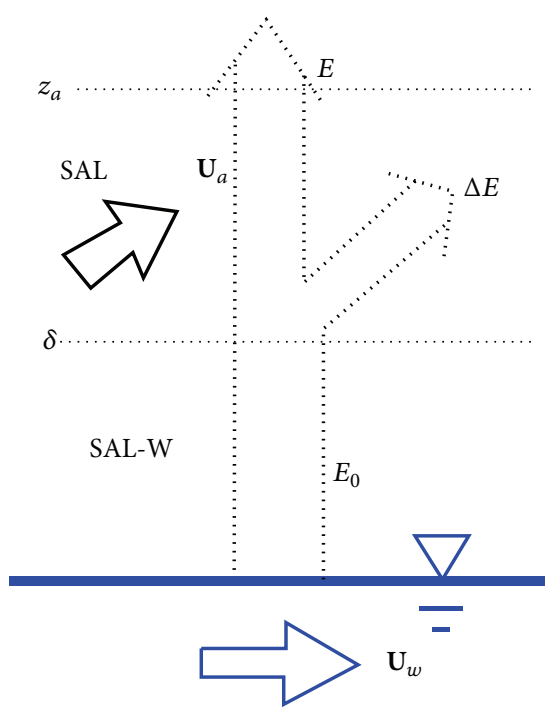

FIgURE 2: Schematic diagram of the double-deck surface air layer (DSAL) formed over the running water. See text for symbols.

vertical profiles of wind speed and humidity prevail in the two sublayers and the vapor flux is also supposed to be invariable with height, we get

$$
\begin{aligned}
& A=\frac{18 k^{2}}{R T\left\{\ln \left(\delta / z_{w 0}\right)\right\}^{2}}, \\
& B=\frac{18 k^{2}}{R T\left\{\ln \left(z_{a} / \delta\right)\right\}^{2}},
\end{aligned}
$$

where $z_{w 0}$ is the roughness length of a running water surface, $R$ is the gas constant, $T$ is the absolute temperature, and $k$ is the von Kármán constant $(=0.4)$ [14]. The roughness length in the SAL is supposed to be $\delta$. The condition of continuity for the vapor flux at the boundary between the two sublayers gives the following relation:

$$
E=A U_{w}\left(e_{w}-e_{a \delta}\right)=B U_{a}\left(e_{a \delta}-e_{a}\right),
$$

where $E$ is the rate of evaporation. From (3) the water vapor pressure at height $\delta$ is

$$
e_{a \delta}=\frac{\left(e_{w}+\left(B U_{a} / A U_{w}\right) e_{a}\right)}{\left(1+B U_{a} / A U_{w}\right)} .
$$

Thus, $E$ can be expressed as

$$
E=\frac{A}{1+A U_{w} / B U_{a}} U_{w}\left(e_{w}-e_{a}\right) .
$$

As a result, we can estimate the rate of evaporation from running water surfaces using (5), which is a function of the wind speed, $U_{a}$, and the water flow speed, $U_{w}$.

In two special cases in which the surface wind blows in the same direction as the stream, when the relative wind speed is $\left|U_{a}-U_{w}\right|$, while, in the opposite direction, when the relative wind speed is $\left|U_{a}+U_{w}\right|$, the double-deck surface air layer 
does not develop and the usual single-story boundary layer is formed. Therefore, the rate of evaporation can be expressed as

$$
E=A_{s}\left|U_{a} \mp U_{w}\right|\left(e_{w}-e_{a}\right),
$$

where $A_{s}$ is the bulk coefficient for these special cases. In these cases, the air always flows over a running water surface, and hence the wind fetch is unlimited and there is no advection. In other usual cases, however, we are faced with the advection phenomenon.

We can suppose that there is no advection in the SAL$\mathrm{W}$ as in the special cases described above. In the SAL, however, we cannot avoid some advection effects. When the advection occurs in the SAL, the condition of continuity at the boundary between the two sublayers is written as

$$
E^{\prime}=A U_{w}\left(e_{w}-e_{a \delta}^{\prime}\right)=B^{\prime} U_{a}\left(e_{a \delta}^{\prime}-e_{a}\right)
$$

where primed symbols represent quantities under conditions of advection. The bulk coefficient $B^{\prime}$ is equal to $B$ plus an increment due to the advection, and hence $B^{\prime}>B$, and, as a result, $E^{\prime}>E$ as is evident from (5). Kobayashi et al. [15] showed that if the advection was disregarded, the rate of evaporation $E$ calculated from (5) underestimated the actual evaporation rate $E_{0}=E^{\prime}$, on average, by $10-20 \%$.

\section{Field Experiments}

3.1. Study Area. The study area is located in the irrigation area in the middle reaches of Heihe River in northwestern China (Figure 1). The land cover in the study area consists of cropland cultivated with maize and vegetables, apple orchards, windbreak forests, and built-up areas.

The observation points were deployed in the Yingke irrigation district in the suburbs of Zhangye City (Figures 1(b) and $1(\mathrm{c}))$. The study area is the typical district in the Zhangye oasis (1400-1600 $\mathrm{m}$ a.s.l.), which is a core part of the middle reaches of Heihe River. The annual mean temperature is $7.0^{\circ} \mathrm{C}$, the annual mean precipitation is $124.9 \mathrm{~mm}$, and the potential evaporation is more than $2000 \mathrm{~mm}$.

The alternation irrigation system is adopted in this district. One round of irrigation (preplant irrigation) is taken in spring, three rounds are taken in summer, and two rounds including postharvesting irrigation are taken in autumn, respectively. The irrigation schedule is made by the local government. The present observation was conducted at a main canal (IOp), named intensive observation, and lateral canals (COp1), named continuous observation (Figure 1). The observation point COp1 was located in a built-up area without shelterbelts. The observation point IOp was situated in cropland about $1.5 \mathrm{~km}$ southwest of COp1.

The canals at which observations were made were constructed using precast concrete walls with designed thickness $10 \mathrm{~cm}$. The canal has a round-bottomed triangle cross section, and the gap between the concrete walls and the ground is stuffed with porous material such as gravels and dry sands. Therefore the insulation against heat of the walls is very good, and hence the heat flux through the walls was neglected in this analysis [7].

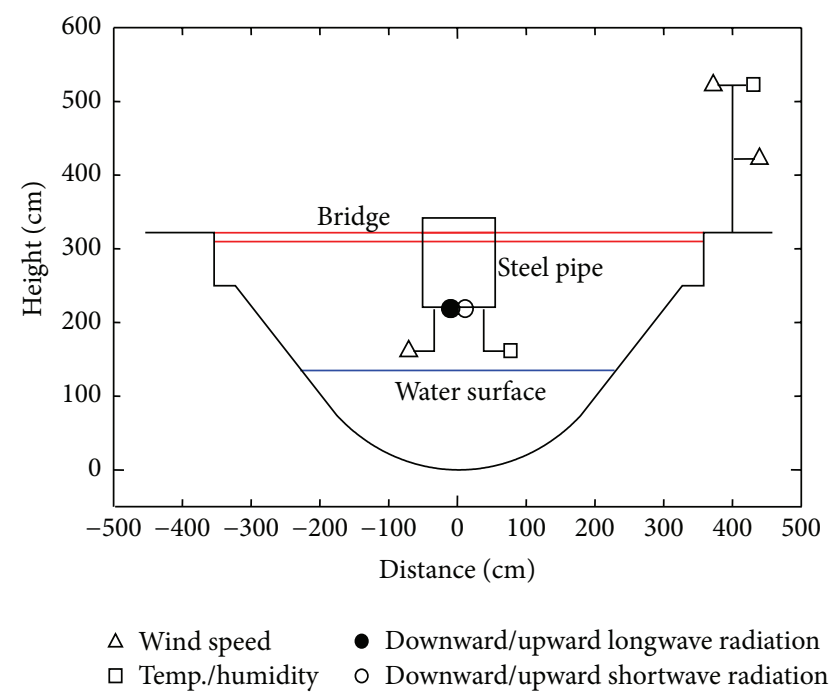

FIgURE 3: Cross section of the main canal and observation instruments installed at IOp.

3.2. Intensive Observation. In order to test the DSAL model, an intensive observation was conducted at the point IOp during the two-day period, July 16 and 17, 2013. The schematic diagram of the observation system is shown in Figure 3. The top width of the canal was $6.6 \mathrm{~m}$, the side slope was $1: 1.3$, and the water flowed toward the ESE. The air current speed was measured at a height of $0.12 \mathrm{~m}$ above the flowing water surface at the center of the canal with a hot-wire anemometer. Air temperature and humidity were measured at about $0.15 \mathrm{~m}$ above the water surface with a HUMICAP sensor. The flowing speed of water was measured by the float method, and the water temperature was measured by fetching water with bucket and reading with mercury thermometers. On the right bank of the canal, the surface wind speed and direction were observed using an aerovane-type anemometer and the air temperature and humidity were observed with a HUMICAP sensor at a height of $2 \mathrm{~m}$ above the ground, or about $5 \mathrm{~m}$ above the flowing water surface. The air movement just above the flowing water surface was visualized by a wisp of smoke produced by burning an incense stick and the height $\delta$ was measured with a vertical hanging ruler over water surface of the canal.

3.3. Continuous Observation. At one of the observation points (COp1), the rates of evaporation from irrigation canals were estimated by the heat balance method [16] and by the aerodynamic method based on the DSAL model. The top width was $1.8 \mathrm{~m}$ and the side slope was $1: 1$. The cross section was measured in the field and described before irrigation. Continuous observation was conducted at the observation point during the summer months of 2013, from June 8 to July 8 , because irrigation was practiced in rotation in the irrigation district, and the canal would have water every about 20 days, and every rotation would last 3 5 days, so the continuous observation had 7 whole days' observation data, and they are June 9 10, June 30, and July 1 4, respectively. In this paper, the results obtained on the 7 days at point COp1 are 
shown and discussed. A straight canal section $148 \mathrm{~m}$ long was selected as the observation site, which was a newly built concrete-lined canal, and thus we can neglect leakage losses from the heat balance point of view. The canal runs straight and the water flows uniformly and steadily.

The automatic weather station (AWS) was set on the right bank of the canal near the midpoint of the section of canal under observation. Data obtained in the continuous observation were through three means, namely, automatic weather station (AWS), automatic logging water level meter, and manual measurement, respectively. The AWS was set up on the side and in the middle of the selected $148 \mathrm{~m}$ canal, and it contained two temperature probes, two hygrometers, the anemograph, and the net radiation sensor (CNR4). In the AWS system, one temperature probe, one hygrometer, and the anemograph were installed about $2 \mathrm{~m}$ above the ground, and the other temperature probe and hygrometer were equipped above the water surface. The net radiation sensor was set up very close to the water surface in order to get true net radiation. Automatic logging water level meters were divided into two groups, one group for the upstream the other for the downstream end. They were installed on the bottom of the canal before the canal had water. From manual measurement, we can obtain water temperature, water flow speed, and also water level; manual measurement was going on in the upstream and downstream end at the same time. The variables measured and instruments used in this observation are listed in Table 1.

Net radiation $\left(R_{N}\right)$ was calculated from the equation $R_{N}=(1-\alpha) R_{s \downarrow}+\varepsilon\left(R_{L \downarrow}-\sigma T_{w}{ }^{4}\right)$, using the measurements of short-wave $\left(R_{s \downarrow}\right)$ and long-wave $\left(R_{L \downarrow}\right)$ downward radiation, at the same time, considering the diurnal change of the albedo $(\alpha)$ determined by field experiment, water temperature $\left(T_{w}\right)$, and the emissivity $(\varepsilon)$ of 0.99 . Water temperature, water level, and water flow speeds at two points specified in the upstream and downstream ends of canal were manually measured every hour or half an hour.

For safety's sake we set the instruments up in the early morning at the site and dismantled them in the evening. Thus, the observation time was only in the daytime from 0700 to 1900 BST.

\section{Results and Discussion}

4.1. Intensive Observation. We analyzed the results of the intensive observation and published them in a local journal of Japan $[11,15,17]$. Therefore, only main results are reproduced here. Figure 4 shows the relationship between the thickness of SAL-W, $\delta$, and the air current speed measured at $0.12 \mathrm{~m}$ above the flowing water surface, $U_{a(0.12)}$. The thickness was defined as the height at which the current-wise (from WNW to ESE) component of the air current produced by the flowing water disappeared. The flow speed of water in the canal, $U_{w}$, was $3.3 \mathrm{~m} \mathrm{~s}^{-1}$ on July 16, while the average surface wind speed for the observation period was about $0.6 \mathrm{~m} \mathrm{~s}^{-1}$ and its direction was SSE. On July 17 , however, the average surface wind speed was about $2.4 \mathrm{~m} \mathrm{~s}^{-1}$ and its direction was NNE, although the flow speed of water was almost the same as the day before.
TABLE 1: General descriptions of the instruments installed at station COp1.

\begin{tabular}{lccc}
\hline Variables & Instruments & $\begin{array}{c}\text { Interval } \\
(\mathrm{min})\end{array}$ & $\begin{array}{c}\text { Height above } \\
\text { water surface } \\
(\mathrm{m})\end{array}$ \\
\hline $\begin{array}{l}\text { Air temperature \& } \\
\text { humidity }\end{array}$ & $\begin{array}{c}\text { HMP45AC } \\
\text { (VAISALA) } \\
\text { 010C-1 } \\
\text { Wind speed }\end{array}$ & 5 & 2 and 0.45 \\
Radiation & $\begin{array}{c}\text { CNRT ONE) } \\
\text { CNR4 }\end{array}$ & 5 & 2.45 \\
$\begin{array}{l}\text { Water temperature } \\
\text { \& flow speed }\end{array}$ & $\begin{array}{c}\text { \& Flowatch } \\
\text { \& Flometer } \\
\text { (NTECH) }\end{array}$ & 30 or 60 & See text \\
Water level & HOBO & 5 & - \\
\hline
\end{tabular}

The values of $U_{a(0.15)}$ were larger on the first day under calm weather conditions than those on the second day under windy conditions, which suggests that the currentwise momentum transported from the running water surface upward was damped quickly with height under larger downward transportation of wind-wise momentum. On each observation day, however, $\delta$ changed conversely with $U_{a(0.12)}$, which implies that the SAL-W was in pulsatile motion, and the air current speed increased with decreasing thickness, and vice versa. Since the water temperature $\left(15.2^{\circ} \mathrm{C}\right)$ was lower than the air temperature by about $10^{\circ} \mathrm{C}$, it seems that wavy motions developed in the thermally stratified air flow just above the surface of flowing water. The frequency is estimated to have been lower than $0.25 \mathrm{~h}^{-1}$. These results suggest that the SAL-W with air temperatures lower than those in the SAL are formed in a dynamic manner, namely, internal wave near the flowing water surface in irrigation canals.

We can measure $\delta$ in the field by visual inspection as described above, but we can also substantiate the existence of such a specified height by comparing the vapor pressure at height $\delta$ calculated from (4) based on this model, $e_{a \delta}$, and the vapor pressure observed in the proximity of height $\delta$ in the field, $e_{a}$. Since the vertical change in vapor pressure near the boundary between the two sublayers is expected to be small, the measurement made at $0.15 \mathrm{~m}$ above the water surface, $e_{a(0.15)}$, should be almost the same as the value of $e_{a \delta}$ because $\delta$ ranged between $0.1 \mathrm{~m}$ and $0.4 \mathrm{~m}$ during the observation period (Figure 4) [17].

The bulk coefficients $A$ and $B$ were calculated from (2) by substituting $10^{-5} \mathrm{~m}$ for $z_{w 0}$, with $z_{a}=5 \mathrm{~m}$ and $\delta=$ $0.2 \mathrm{~m}$. Figure 5 shows the relationship between $e_{a \delta}$ and $e_{a(0.15)}$. We can see that $e_{a(0.15)}$ was, on average, smaller than $e_{a \delta}$, the reason for which seems to be the advection [15]. The high correlation between $e_{a \delta}$ and $e_{a(0.15)}$ is circumstantial evidence that the DSAL model is reliable, although the effect of advection of the order of 10 20\% on the vapor pressure can be recognized [15].

4.2. Continuous Observation. The results of the continuous observation were analyzed using the two methods, the aerodynamic method based on the DSAL model and the 


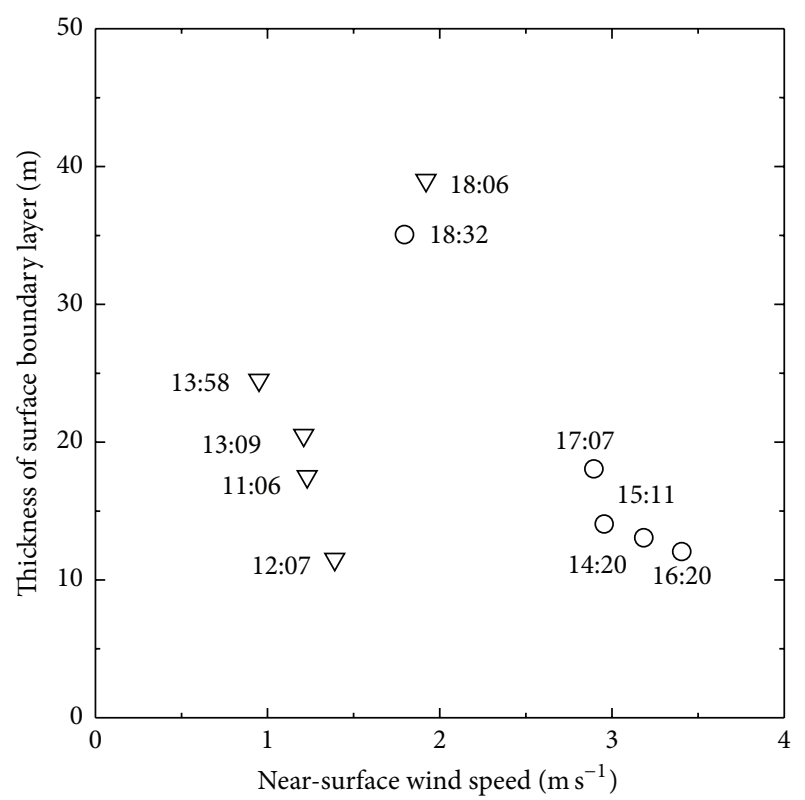

O July 16

$\nabla$ July 17

FIGURE 4: Relationship between $\delta$ and $U_{a(0.12 \mathrm{~m})}[17]$.

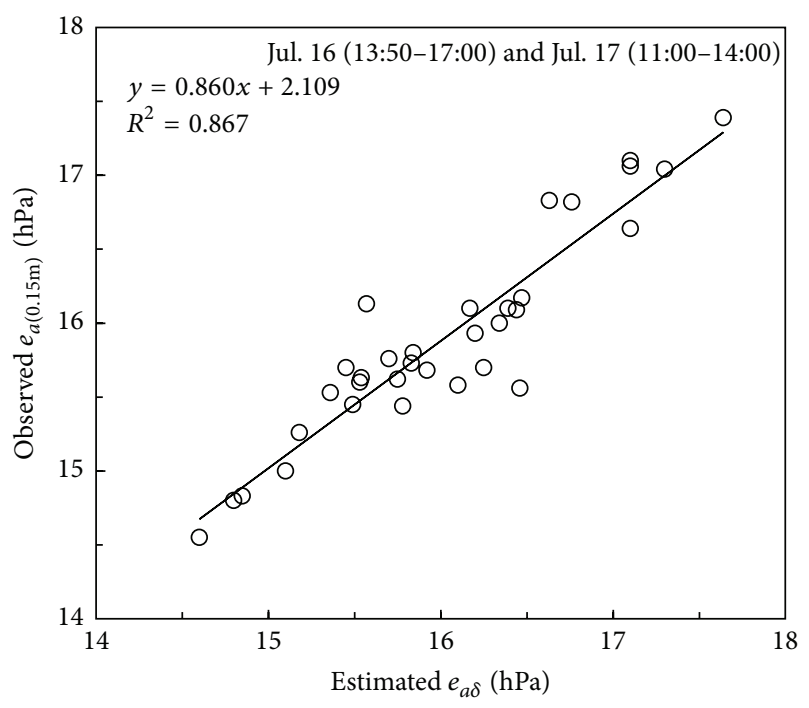

Figure 5: Comparison of $e_{a \delta}$ calculated from (4) and $e_{a(0.15 \mathrm{~m})}$ measured in the field [17].

heat balance method. Since the heat balance method was discussed in a companion paper [16] and it seems familiar to everyone, the details of the method were omitted here for the sake of brevity. In order to analyze the heat balance on the water flowing in the section $148 \mathrm{~m}$ long, the discharge and water temperature have to be measured at the upstream and downstream ends. The discharge was calculated by equation $Q=c v t$, where $c$ is area of the water cross section, $v$ is the water speed, and $t$ is the passing time of water flow through the $148 \mathrm{~m}$ canal. The water temperature was measured at the

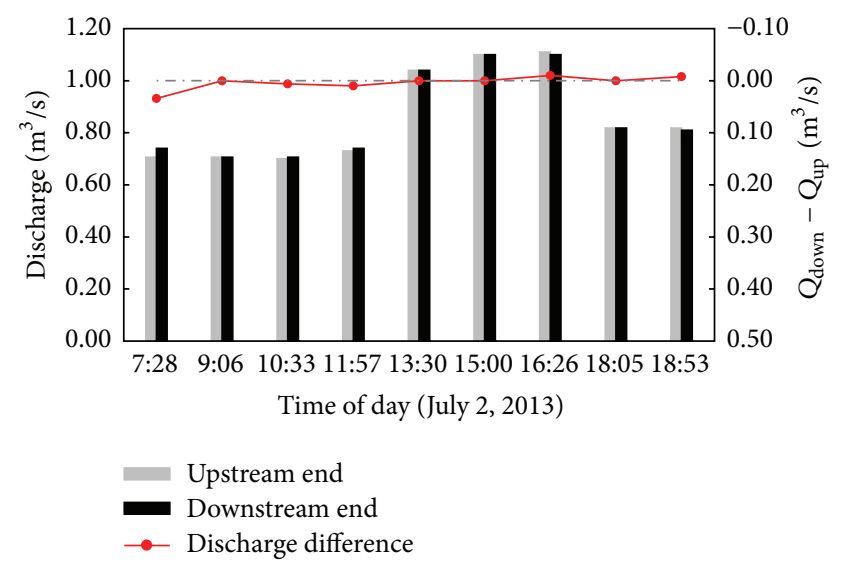

FIgURE 6: Diurnal variations of the discharge at the upstream and downstream ends (July 2, 2013).

upstream and downstream ends by mercury thermometer at the same time. Furthermore, the net radiation at the water surface is another important element of heat balance on the flowing water and the calculation method was the same as in intensive observation. By way of example the diurnal variations of such elements on July 2, 2013, are shown below.

The diurnal variation of the discharge at the upstream and downstream ends is shown in Figure 6. The discharge difference equals discharge in the downstream minus that in the upstream end. We can see that the discharge changed with time but the amounts at both the ends were approximately equal to each other, and the possible errors were of the order of one percent; hence, the leakage can be neglected. Evaporation losses, of course, cannot be neglected as regards the energy balance, because the ratio of evaporation losses to the discharge in units of energy is larger than 1000 times the ratio in units of volume, for the ratio can be expressed as $L / c \rho \Delta T$ ( $L$ : heat of vaporization, $c \rho$ : heat capacity of water, and $\Delta T$ : difference in water temperature between both ends). We used the average of the two discharges measured at both ends.

The diurnal variation of the water temperature at both ends of the canal is shown in Figure 7. The temperature difference equals water temperature measured at the downstream minus that measured at the upstream end. The water temperature was measured with one glass thermometer graduated in every $0.005^{\circ} \mathrm{C}$. The figure shows an interesting and wellmarked feature that during a period when water temperature rises and reaches its daily maximum around $1400 \mathrm{BST}$, the water temperature at the upstream end was lower than that at the downstream end, while the reverse was true during a period when the water temperature falls. On the other days, except for rainy days, during the observation period, the difference in water temperature between the upstream and downstream ends showed the similar diurnal variation.

Although the net radiation changed irregularly or fluctuated sharply due to weather conditions, there appears to have been a tendency for net radiation to be large when the water temperature rose in the morning and to be small when it fell in the afternoon (Figure 8). These results suggest that, in 


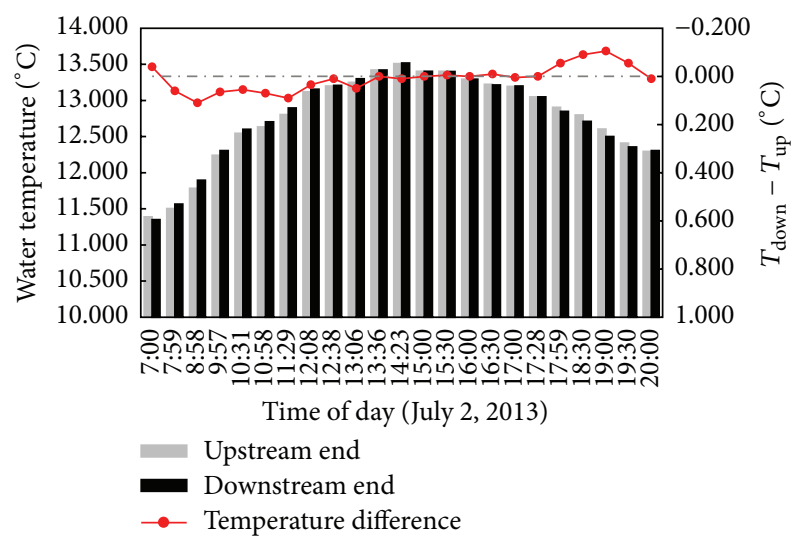

Figure 7: Diurnal variations of the water temperature at the upstream and downstream ends (July 2, 2013).

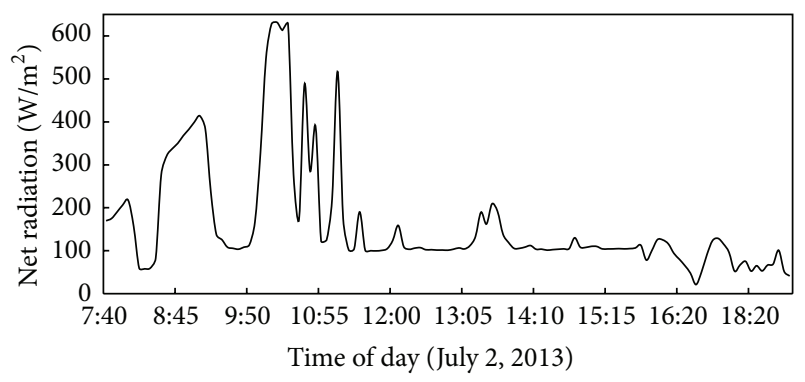

FIGURE 8: Diurnal variation of the net radiation in the daytime (July 2, 2013).

general, the water temperature rose by absorbing radiation in the morning and the energy flowed in the canal and decreased due to releasing energy to the surroundings and the energy flowed out from the canal; evaporation occurred during the whole process. The water temperature rise or decrease just resulted from the net energy that flowed in or out of the canal.

The diurnal variation of the evaporation rate obtained by the heat balance method on July 2 is shown in Figure 9, along with those of other three days (June 9, June 30, and July 4) exhibiting a similar diurnal variation pattern. The evaporation rate fluctuated sharply in the afternoon when the net radiation was small and evaporation rate was relatively large. These fluctuations seem to be mainly due to the errors in measuring the difference in water temperature between the upstream and downstream ends. For example, if the measurement error of the temperature difference is $0.005^{\circ} \mathrm{C}$, it corresponds to the measurement error of the radiation of $100 \mathrm{Wm}^{-2}\left(Q \sim 1 \mathrm{~m}^{3} \mathrm{~s}^{-1}, L W \sim 200 \mathrm{~m}^{2}\right)$ at the water surface. Thus in the afternoon when the net radiation was of the order of $100 \mathrm{~W} \mathrm{~m}^{-2}$ the measurement error of the water temperature seems to have caused larger errors in the estimation of evaporation rate than in the morning. These results suggest that the heat balance method is not suitable for estimating the diurnal change of the evaporation rate from canals of this size and discharge, and attention must be given to the cumulative evaporation instances for a period of time longer than a few days.

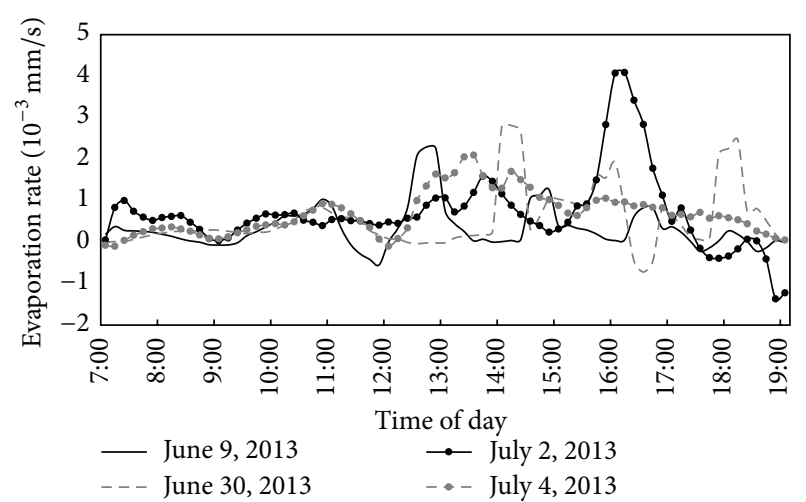

FIGURE 9: Diurnal variations of the evaporation rate of four days (2013).

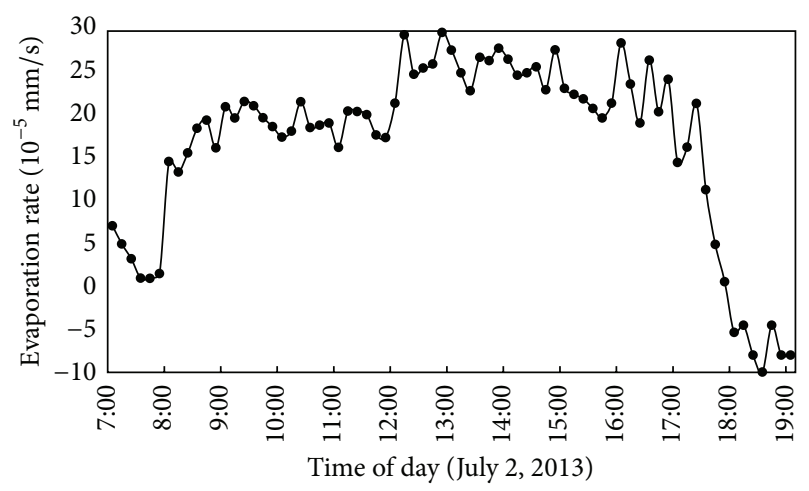

FIGURE 10: Diurnal variation of the evaporation rate obtained by the aerodynamic method based on the DSAL model (July 2, 2013).

4.3. Comparison of the Two Methods. The diurnal variation of the evaporation rate estimated by the aerodynamic method based on the DSAL model on July 2 was shown in Figure 10. The bulk coefficients were obtained from (2) by inserting the numerical values, with $z_{a}=2 \mathrm{~m}, \delta=0.1 \mathrm{~m}$, and $z_{w 0}=$ $10^{-5} \mathrm{~m}$. The rate of evaporation was calculated from (5), when a representative water flow speed of $2.8 \mathrm{~m} \mathrm{~s}^{-1}$ was used. As shown in Figure 9, evaporation rate on July 2 was also calculated by the heat balance method; however, it seemed that results got by two methods were very different from each other. Actually, they were having the same order. This is because the derived values of evaporation rate by the heat balance method have the magnitude with order of $10^{-3} \mathrm{~mm} \mathrm{~s}^{-1}$ except some time, such as 12:00, 14:00, and 16:00, as shown in Figure 9, while those estimated by the DSAL method ranged from $10 \times 10^{-5} \mathrm{~mm} \mathrm{~s}^{-1}$ (0.0001) to 30 $\times 10^{-5} \mathrm{~mm} \mathrm{~s}^{-1}(0.0003)$ during the core period of daytime in Figure 10. As a result, except for the limited periods, values calculated from both methods had the same order on July 2 , 2013. Similar tendencies were confirmed in the derived values by the two methods on other days according to our analysis.

As can be seen in Figure 7, water temperature was very low, and hence the rate of evaporation was almost zero or negative in the morning and evening. These qualitative characteristics were consistent with those results obtained 
by the heat balance method, although the numerical values of the estimates seem different from each other (Figures 9 and 10). The major cause of this difference seems to be the insufficient accuracies of water temperature measurements as is discussed above. Measuring errors of water temperature were unavoidable problems when utilizing the heat balance method to estimate the evaporation from the moving water; hence, the sharp increases or spikelet drops suddenly occurring during the daytime in Figure 9 were also unavoidable, so the result obtained by the heat balance method was unstable in practice. From Figure 10, it is indicated that the values from the DASL method are stable; there is no spikelet changes even on such short time interval of 10 minutes. This is one of the important advantages of the DSAL compared to the heat balance method.

The cumulative evaporation instance for a time period 0700 to 1900 BST is called the "daytime evaporation" hereafter. The scatter plot of daytime evaporation instances obtained by the heat balance method and the aerodynamic method based on the DSAL model is shown in Figure 11. Here the data obtained on June 11 are not shown because the daytime evaporation estimated by the heat balance method was negative due to unusually large measurement errors, maybe human errors, of the water temperature. Although the effect of accuracies of water temperature measurements is not sufficiently small, it seems reasonable to conclude that the rate of evaporation estimated by the aerodynamic method based on the DSAL model is equal in order of magnitude to or somewhat smaller, due to advection [15], than that by the heat balance method.

4.4. Evaporation Loss of Irrigation Water in Transport. The evaporation loss of irrigation water in transport from the intake to the fields through a canal with length $L$ is expressed as

$$
R=E \frac{W L}{Q},
$$

where $E$ is the rate of evaporation, $W$ the width of water surface in the canal, and $Q$ the discharge. Since the rate of evaporation changes with time of day, $R$ changes depending on the transportation spell. If we assume that $E=10^{-4} \mathrm{~mm} \mathrm{~s}^{-1}=$ $10^{-7} \mathrm{~m} \mathrm{~s}^{-1}, U=2.8 \mathrm{~m} \mathrm{~s}^{-1}$, and $Q=1 \mathrm{~m}^{3} \mathrm{~s}^{-1}$, then we get $R=$ $10^{-7} W L$. This result suggests that when $L$ is $10^{4} \mathrm{~m}$ and $W$ is $1 \mathrm{~m}, R$ is $0.1 \%$, but since the transportation spell is about 60 minutes, $R$ can be larger or smaller than this value depending on the time of day and can be even negative at night. Jazira [18] estimated the evaporation loss in the middle reaches of Heihe River to be about $8 \%$. If $W L / Q$ averaged over the irrigation district can be of the order of $10^{5} \mathrm{~m}^{-1} \mathrm{~s}, R$ is of the order of one percent. The evaporation loss calculated by Jazira covered all five levels of canals in the middle reaches of Heihe River, and some types of canal would have low evaporation, such as lateral canal and field canal for deep and narrow water, while some types of canal would have high evaporation for the wide and shallow water, such as main canal, branch canal, and field ditches. In the study, the lateral canal was used for estimating evaporation, so it was reasonable that our results were lower than their results.

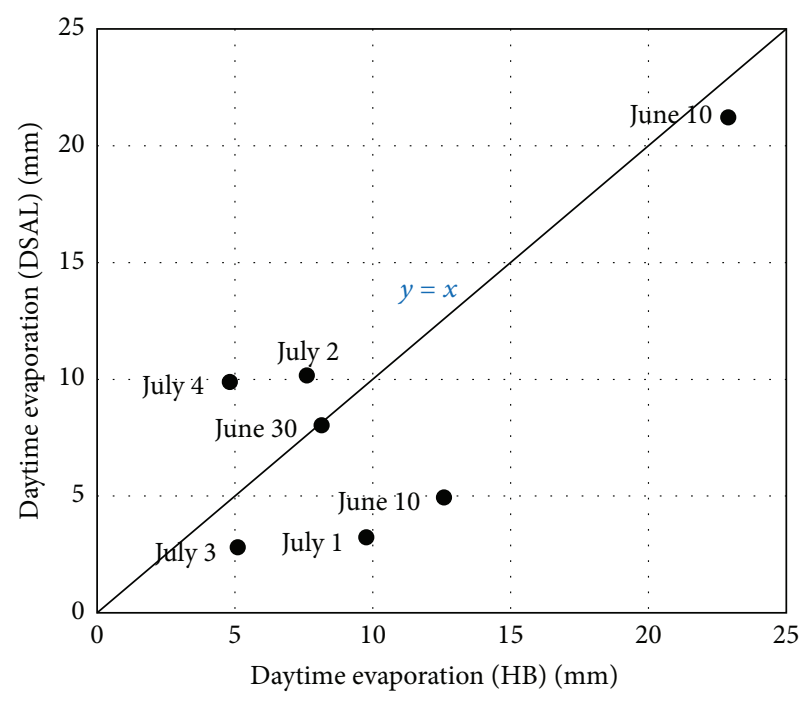

FIgURE 11: Comparison of the daytime evaporation instances obtained by the heat balance (HB) method and those obtained by the aerodynamic method based on the DSAL model (DSAL) (2013).

\section{Concluding Remarks}

The double-deck surface air layer (DSAL) model which describes the composite surface air layer formed over irrigation canals was proposed by Kobayashi et al. [11], and one of the purposes of this study is to test the model against the field observation. As a result, it was verified that the DSAL model is reliable and the aerodynamic method based on the DSAL model is effective in estimating the evaporation from irrigation canals.

The most popular method that has been used in estimating the evaporation from canals or channels is the heat balance method. In case of irrigation canals, however, the flow speed of water is rather high and the width of the water surface is relatively narrow. Thus the accuracy of measuring water temperature exerts a crucial influence on the precision of determining the heat balance terms. Hence the heat balance method was only applicable for estimating the cumulative evaporation for a time period longer than a few days. A comparison of the daytime evaporation instances estimated by the aerodynamic method based on the DSAL model and those by the heat balance method led to the conclusion that both the methods yield the results that are equal in order of magnitude to each other.

The evaporation loss of irrigation water in transport varies directly with the rate of evaporation $(E)$, the width of water surface in the canal $(W)$, and the distance from the intake to the fields $(L)$ and varies inversely with the discharge $(Q)$. The rate of evaporation changes with time of day and is almost zero or negative in the nighttime, and so the evaporation loss can be reduced by making a rational irrigation schedule. We evaluated from these experiments that the evaporation loss in transport in this region is of the order of one percent at most. 


\section{Conflict of Interests}

The authors declare that there is no conflict of interests regarding the publication of this paper.

\section{Acknowledgments}

The authors wish to thank Professor Kitano and Messrs. Nomiyama and Hisaeda of Kyushu University and Professor Cho and Mr. Tagawa of Saga University for assisting them in the field observations. They also thank Dr. Y. Wu and G. H. Huang and S. Cheng of Cold and Arid Regions Environmental and Engineering Institute, CAS, for their kind assistance in conducting the field observations. This work is supported by the CAS Action-Plan for West Development (Grant no. KZCX2-XB3-15) and the National Natural Science Foundation of China (Grants nos. 91125002, 41271359, and 41301363).

\section{References}

[1] Y. Huang, G. Fipps, S. J. Maas, and R. S. Fletcher, "Airborne remote sensing for detection of irrigation canal leakage," Irrigation and Drainage, vol. 59, no. 5, pp. 524-534, 2010.

[2] H. E. M. Moghazi and E.-S. Ismail, "A study of losses from field channels under arid region conditions," Irrigation Science, vol. 17, no. 3, pp. 105-110, 1997.

[3] D. L. Mcjannet, I. T. Webster, M. P. Stenson, and B. S. Sherman, Estimating Open Water Evaporation for the MurryDarling Basin. A Report to the Australian Government from the CISRO Murray-Darling Basin Sustainable Yields Project, CSIRO, Canberra, Australia, 2008.

[4] A. Higashi and T. Hanyu, "A study on the temperature rise of water by running it through channels," Journal of Agricultural Physics, vol. 2, pp. 55-69, 1952.

[5] Y. Mihara, Z. Uchijima, S. Nakamura, and K. Ohnuma, "A study on heat balance and water temperature rising of the warming pond," Bulletin of the National Institute of Agricultural Sciences Japan A, vol. 7, pp. 1-44, 1959 (Japanese).

[6] Y. Mihara, Z. Uchijima, and S. Nakamura, "A study on heat balance of the water warming channels," Bulletin of the National Institute of Agricultural Sciences (Japan) A, vol. 7, pp. 45-68, 1959 (Japanese).

[7] H. E. Jobson, "Thermal modeling of flow in the San Diego Aqueduct, California, and its relation to evaporation," Professional Paper 11221126, United States Government Publishing Office, Washington, DC, USA, 1980.

[8] J. M. Fulford, T. W. Sturm, and M. Asce, "Evaporation from flowing channels," Journal of Energy Engineering, vol. 110, no. 1, pp. 1-9, 1984.

[9] P. J. Ryan and D. R. F. Harleman, "An analytical and experimental study of transient cooling pond behavior," Tech. Rep. 161, R.M. Parsons Laboratory, M.I.T, 1973.

[10] T. Kawahara, "A fundamental study on the temperature rise of irrigation water," Journal of Agricultural Engineering, vol. 21, pp. 224-231, 1953.

[11] T. Kobayashi, S. Liu, W. Wang, and M. Mori, "Modeling of the evaporation from a running water surface," Kyushu Journal of Agricultural Meteorology, Series 2, vol. 22, pp. 1-14, 2013.

[12] D. Molden, T. Oweis, P. Steduto, P. Bindraban, M. A. Hanjra, and J. Kijne, "Improving agricultural water productivity: between optimism and caution," Agricultural Water Management, vol. 97, no. 4, pp. 528-535, 2010.

[13] S. J. Zwart and W. G. M. Bastiaanssen, "Review of measured crop water productivity values for irrigated wheat, rice, cotton and maize," Agricultural Water Management, vol. 69, no. 2, pp. 115133, 2004.

[14] T. Kobayashi, Physics of Agricultural Environment. Laboratory of Remote Sensing and Geospatial Science, CAREEI, CAS, China, 2013.

[15] T. Kobayashi, M. Mori, S. Liu, and W. Wang, "Evaluating the advection effect on the estimates of evaporation from irrigation canals made by a new aerodynamic method," Kyushu Journal of Agricultural Meteorology Series 2, vol. 23, pp. 7-12, 2014.

[16] W. Wang, S. Liu, T. Kobayashi, and M. Kitano, "Evaporation from irrigation canals in the middle reaches of the Heihe River in the Northwest of China-a preliminary study," Journal of the Faculty of Agriculture, Kyushu University, vol. 58, no. 2, pp. 371376, 2013.

[17] M. Mori, S. Liu, W. Wang et al., "An observational study of the structure of surface air layer formed over the running water in an irrigation canal in Northwestern China," Kyushu Journal of Agricultural Meteorology Series 2, vol. 22, pp. 46-49, 2013.

[18] A. Jazira, Study on Water Balance Model of Irrigation Area in the Middle Reaches of Heihe Basin, Hohai University, Nanjing, China, 2006. 

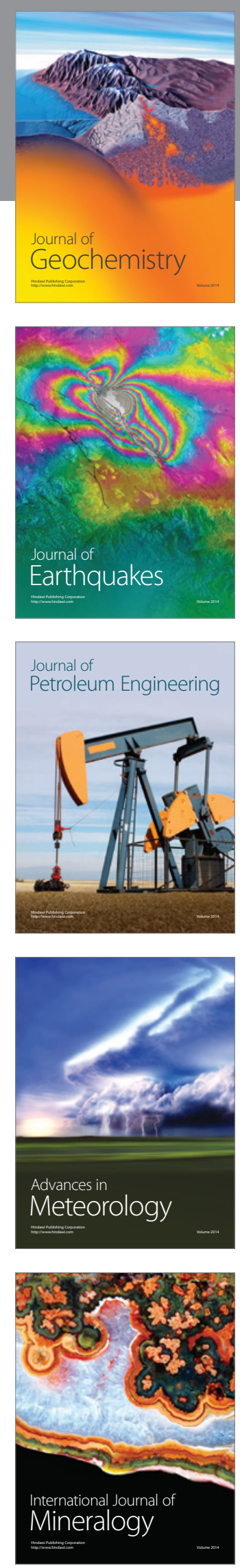
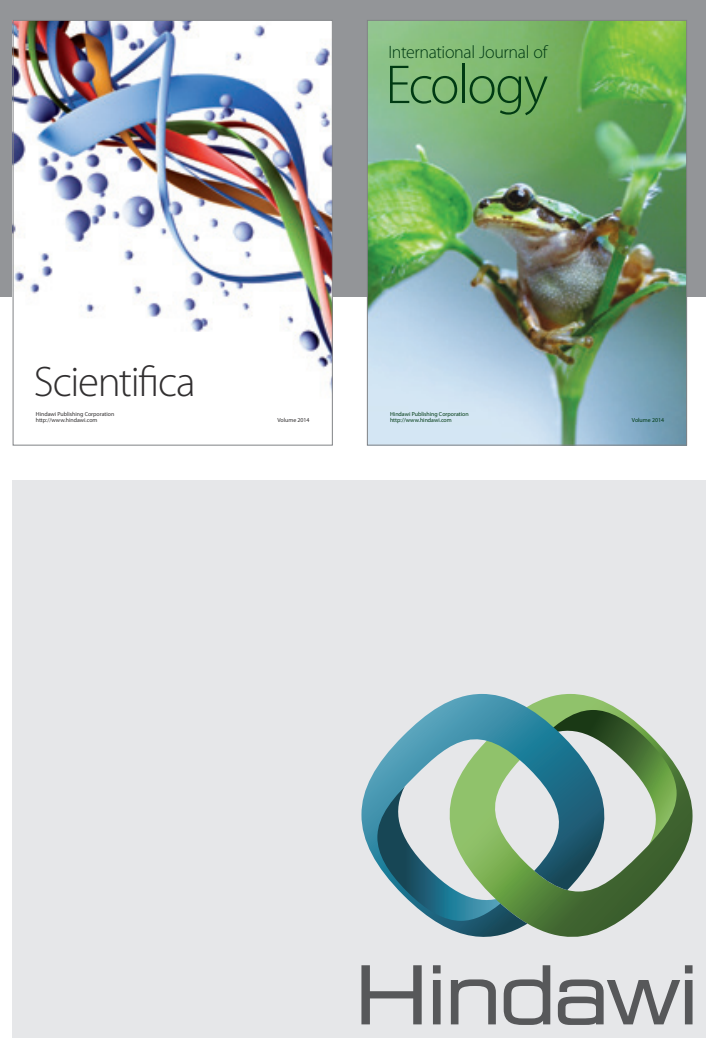

Submit your manuscripts at

http://www.hindawi.com
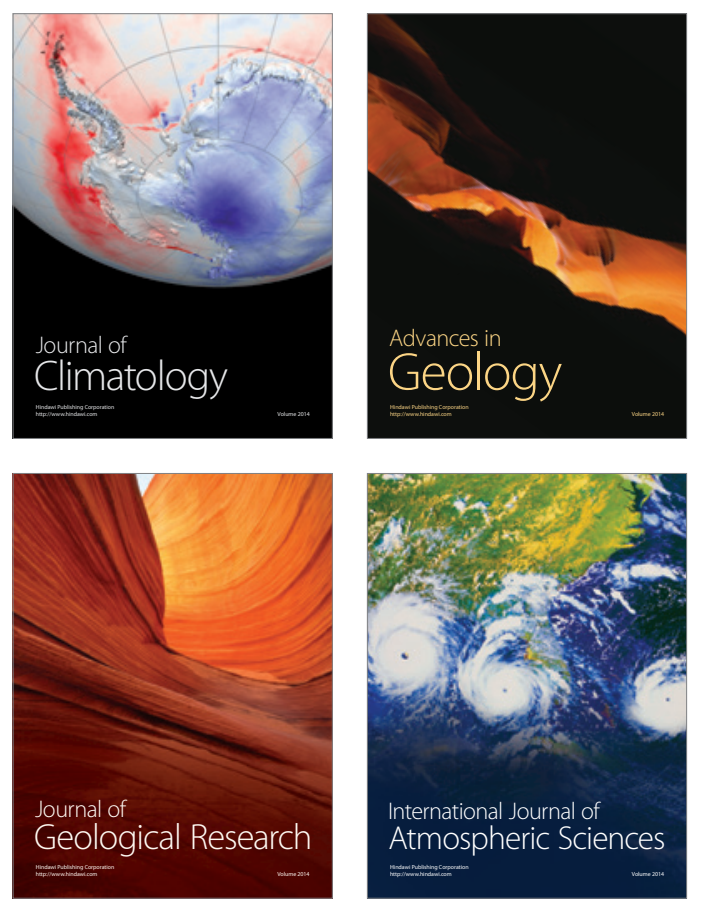

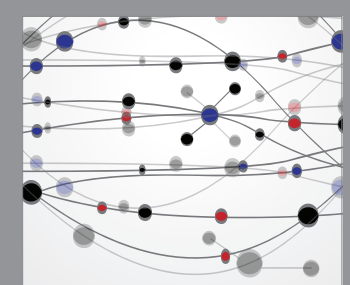

The Scientific

\section{World Journal}
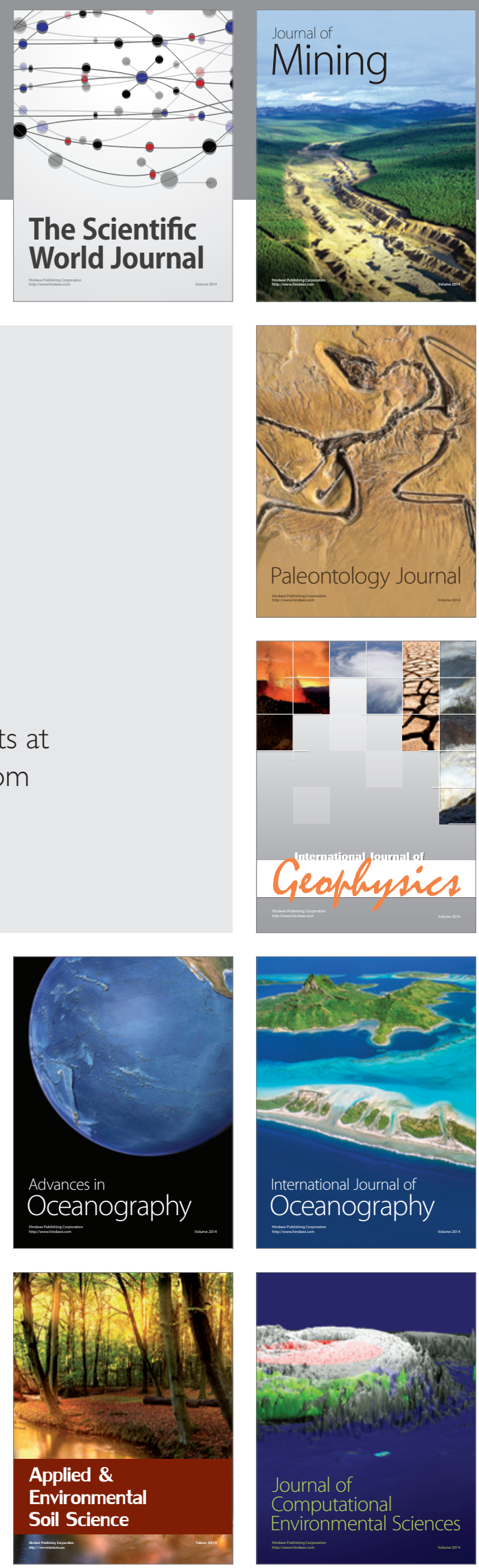